\title{
Flexible Thermoelectric Device Using Thick Films for Energy Harvesting from the Human Body
}

\author{
Han Ki Cho*,**, Da Hye Kim*,***, Hye Sun Sin*,*****, Churl-Hee Cho***, and Seungwoo Han*,***,t \\ *Department of Applied Nanomechatronics, Korea Institute of Machinery and Materials, Daejeon 34103, Korea \\ **Graduate School of Energy Science and Technology (GEST), Chungnam National University, Daejeon 34134, Korea \\ ${ }^{* * *}$ Department of Nanomechatronics, University of Science and Technology, Daejeon 34113, Korea \\ ****Department of Advanced Materials Science and Engineering, Sungkyunkwan University, Suwon 16419, Korea
}

(Received August 11, 2017; Revised October 18, 2017; Accepted October 18, 2017)

\begin{abstract}
A flexible thermoelectric device using body heat has drawn attention as a power source for wearable devices. In this study, thermoelectric thick films were fabricated by cold pressing method using $\mathrm{p}$-type antimony telluride and $\mathrm{n}$-type bismuth telluride powders in accordance with specific loads. Thermoelectric thick films were denser and improved the electrical and thermoelectric properties while increasing the load of the cold pressing. The thickness of the specimen can be controlled by the amount of material; specimens were approximately $700 \mathrm{um}$ in thickness. Flexible thermoelectric devices were manufactured by using the thermoelectric thick films on PI (Polyimide) substrate. The process is cheap, efficient, easy and scalable. Evaluation of power generation performance and flexibility on the fabricated flexible thermoelectric device was carried out. The flexible thermoelectric device has great flexibility and good performance and can be applied to wearable electronics as a power source.
\end{abstract}

Key words : Thermoelectric thick films, Flexible thermoelectric device, Cold pressing, Wearable electronics

\section{Introduction}

$\mathrm{T}$ he world faces a number of problems regarding energy. Demand for fossil energy continues to rise and greenhouse gases produced from the use of fossil energy have become a problem. As a result, various energy industries are being presented as alternatives. ${ }^{1,2)}$ Thermoelectric devices, which are being studied recently, produce electricity by reclaiming wasted heat. ${ }^{3)}$ Thermoelectric devices can directly and reversibly convert thermal energy to electrical energy. Thus, thermoelectric devices are able to be applied for power generation or cooling without noise or vibrations because there are no mechanical driving elements like those in conventional coolers and heaters. ${ }^{4}$

Generally, thermoelectric devices are categorized by the height of the thermoelectric legs. There are bulk type devices with thermoelectric legs heights of a few $\mathrm{mm}$, thin film type devices with the height of a few $\mu \mathrm{m}$, and thick film type devices with the height ranging from tens of $\mu \mathrm{m}$ to hundreds of $\mu \mathrm{m}$. It has been reported that thick film type devices with thermoelectric legs height of at least $30 \mu \mathrm{m}$ are required to secure heat flow.

The use of thermoelectric thick films makes it easy to

${ }^{\dagger}$ Corresponding author : Seungwoo Han

E-mail : swhan@kimm.re.kr

Tel : +82-42-868-7246 Fax : +82-42-868-7884

Corresponding author : Churl-Hee Cho

E-mail : choch@cnu.ac.kr

Tel : +82-42-821-8606 Fax : +82-42-821-8839 impart flexibility of thermoelectric devices while maintaining a constant temperature difference between the upper and lower sides of them.

Fabrication methods of thermoelectric thick films include electroplating and screen printing. Electroplating is cheap and allows for rapid fabrication as well as thickness control. However, the process results in poor surface roughness, poor physical properties, and difficulty in stoichiometric control. ${ }^{6}$ Screen printing is more advantageous for low cost scaling up; however, thick films fabricated through screen printing have high illuminance at micro order, resulting in a lack of connection between the upper or lower substrates and thermoelectric thick films during bonding process, or a reduction of thermoelectric efficiency due to significant increase of resistance. ${ }^{5,7)}$

Conventional bulk type devices are limited in flexibility; however, flexible thermoelectric devices can obtain energy from various heat sources having curved surfaces. This advantage enables applications to wearable devices that use the human body as a heat source; such devices are garnering attention from numerous researchers. ${ }^{8-11)}$ In this study, thermoelectric thick films were prepared by cold press method using thermoelectric powders. Flexible thermoelectric devices were fabricated using them, and their power generation performance and flexibility were evaluated.

\section{Experimental Procedure}

$\mathrm{Sb}_{2} \mathrm{Te}_{3}$ (purity 99.995\%) industrial powder was used as a base material; its particle size was approximately $1 \sim 3 \mu \mathrm{m}$. 
$\mathrm{Bi}_{2} \mathrm{Te}_{3}$ was purchased as ingots and crushed. To prevent oxidation and contamination, a mortar, rather than mechanical ball milling, was used to crush the $\mathrm{Bi}_{2} \mathrm{Te}_{3}$ into powder. The particle size was approximately $800 \mathrm{~nm} \sim 1.5 \mu \mathrm{m} .{ }^{12)}$

Figure 1 shows the cold pressing equipment used to fabricate the $\mathrm{P}$ type $\mathrm{Sb}_{2} \mathrm{Te}_{3}$ and $\mathrm{N}$ type $\mathrm{Bi}_{2} \mathrm{Te}_{3}$ specimens.

Loads of $22.2 \mathrm{kN}$ and $33.3 \mathrm{kN}$ were applied to assess the thermoelectric property change according to the load. The thicknesses of the specimens were controlled using the amount of powder. $0.6 \mathrm{~g}$ of $\mathrm{Sb}_{2} \mathrm{Te}_{3}$ and $0.6 \mathrm{~g}$ of $\mathrm{Bi}_{2} \mathrm{Te}_{3}$ powders were used to fabricate specimens with dimensions of 1 $\mathrm{cm} \times 1 \mathrm{~cm}$ and thicknesses of approximately $700 \mu \mathrm{m} \sim 800$ $\mu \mathrm{m}$.

The Seebeck measurement system of Fraunhofer was used to measure the Seebeck coefficient of the specimens; the Hall measurement system of Ecopia was used to measure the electron mobility and electrical resistivity of them.

A new cold press module was designed and manufactured to fabricate the thick film type thermoelectric leg. The module was designed so that 5 thermoelectric legs with dimensions of $1.5 \mathrm{~mm} \times 1.5 \mathrm{~mm}$ could be fabricated simultaneously. The surface roughness of the thermoelectric leg was improved by surface treating the module to which the load was applied.

Figure 2 shows the fabrication process of the flexible ther-

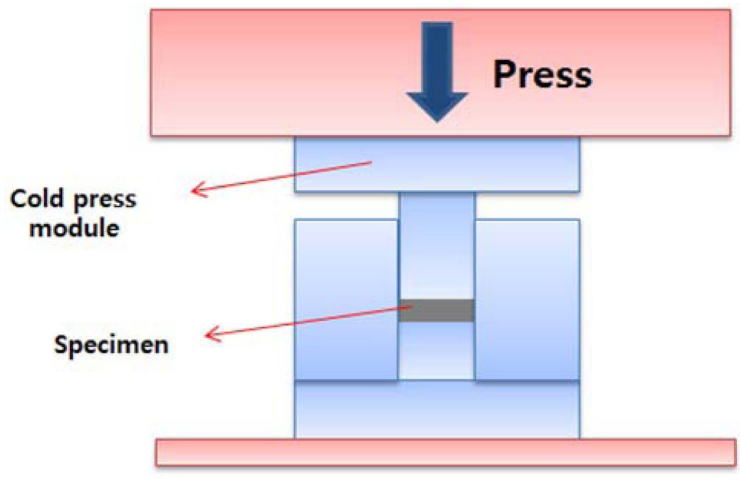

Fig. 1. Schematic of cold pressing equipment of thermoelectric thick films.

(a)

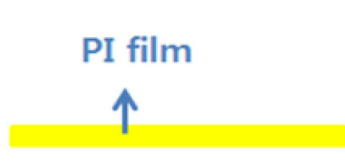

(d)

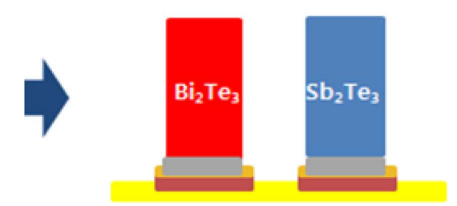

(b)

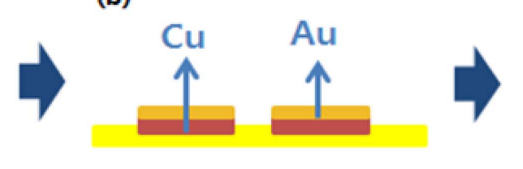

(e)

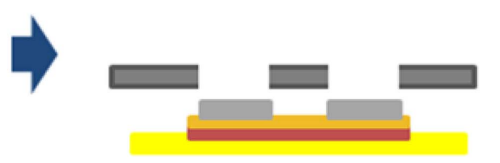

moelectric device. As can be seen in Fig. 2(a), PI with a thickness of $38 \mu \mathrm{m}$ was used. Fig. 2(b) shows the formation of the lower electrode. The lower electrode was patterned using electroplating a $10 \mu \mathrm{m}$ thickness of $\mathrm{Cu}$ (Copper) and a $0.1 \mu \mathrm{m}$ thickness of $\mathrm{Au}(\mathrm{Gold})$ on the PI substrate. Fig. 2(c) shows the solder paste (HeePFM-48W HS-HF(BH)P, HeeSung) deposition using screen printing after attaching a metal mask to the lower electrode to attach it to the thermoelectric leg. Fig. 2(d) shows the fabricated $\mathrm{Sb}_{2} \mathrm{Te}_{3}$ and $\mathrm{Bi}_{2} \mathrm{Te}_{3}$ thermoelectric legs placed on top of the solder paste. Figures 2(e) and (f) show the bonding processes in which the upper electrode and the thermoelectric leg were overlapped using a positioning jig. The flexible thermoelectric device was then fabricated through heat treatment at $217^{\circ} \mathrm{C}$ for $15 \mathrm{~min}$.. Fig. 3 shows the fabricated device composed of 6 pairs with dimensions of $5 \mathrm{~cm} \times 3 \mathrm{~cm}$.

Figure 4 provides a schematic diagram of the evaluation system for power generation performance of flexible thermoelectric devices. To establish a temperature difference, the hot side was heated using a heater and the cold side was cooled by forced convention using a heat sink. A fan was installed next to the heat sink to effectively remove the heat produced by convection heat transfer. The current produced from the flexible thermoelectric device was measured using a digital multimeter (Measurement 2700, Keithley) and the voltage was measured using a digital sourcemeter (Measurement 2400, Keithley). For the variable resistor, a digital rheostat (M642, MEATEST) was used. The internal resis-

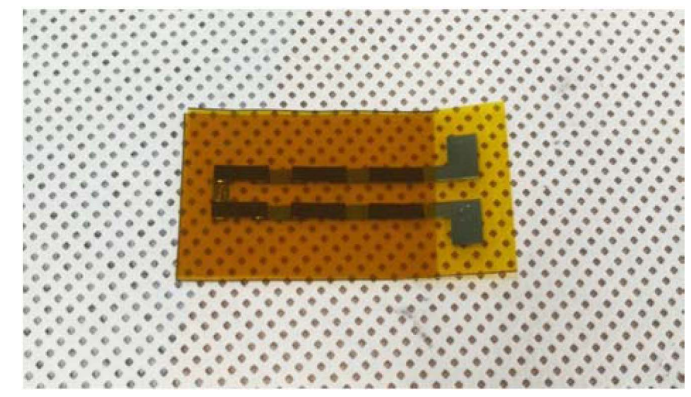

Fig. 3. Fabricated flexible thermoelectric device.

(c)

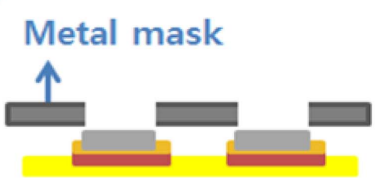

(f)

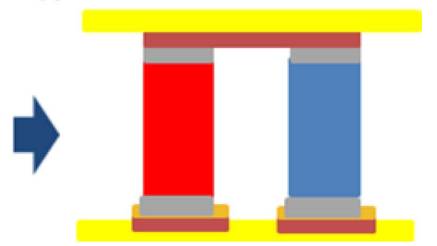

Fig. 2. Fabrication process of flexible thermoelectric device: (a) PI substrate, (b) patterning of lower electrode, (c) screen printing solder paste, (d) arrangement of thermoelectric legs on solder paste, (e) patterning of upper electrode, (f) bonding process between upper electrode and thermoelectric legs. 


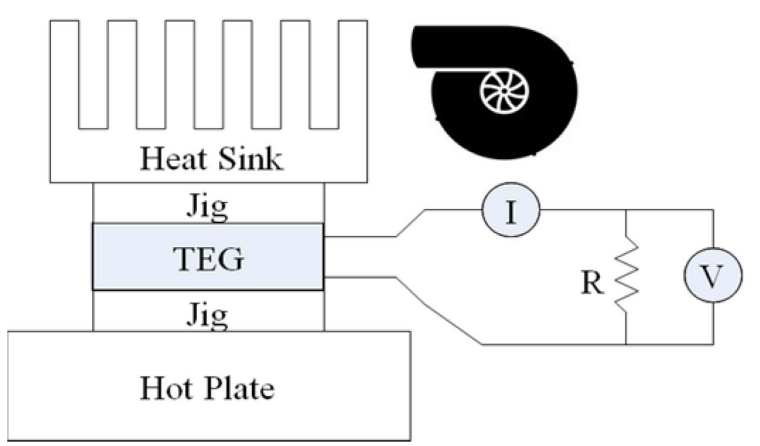

Fig. 4. Schematic of evaluation system for power generation performance of thermoelectric devices.

tance (Measurement 2450, Keithley) of the specimens was accurately measured using the four-wire method. The temperature difference between the upper and lower portions of the flexible thermoelectric device was measured using temperature sensors installed between the heater and the flexible thermoelectric device and between the heat sink and the thermoelectric device. Data acquisition was carried out using an A/D converter (NI, PXIE) and the Labview program.

Figure 5 shows the repeated bending test equipment for the flexible thermoelectric devices. The flexible thermoelectric devices were installed on the actuator of a fatigue testing machine (Tytron 250, MTS). Then, bending load was applied and the bending radius was measured using linear laser equipment (LJ-V7020W, KEYENCE). After the flexible thermoelectric devices were fixed to the jig attached to the actuator, the bending radius was controlled using a computer program connected to the fatigue testing machine. The linear laser equipment irradiates a laser onto the flexi-

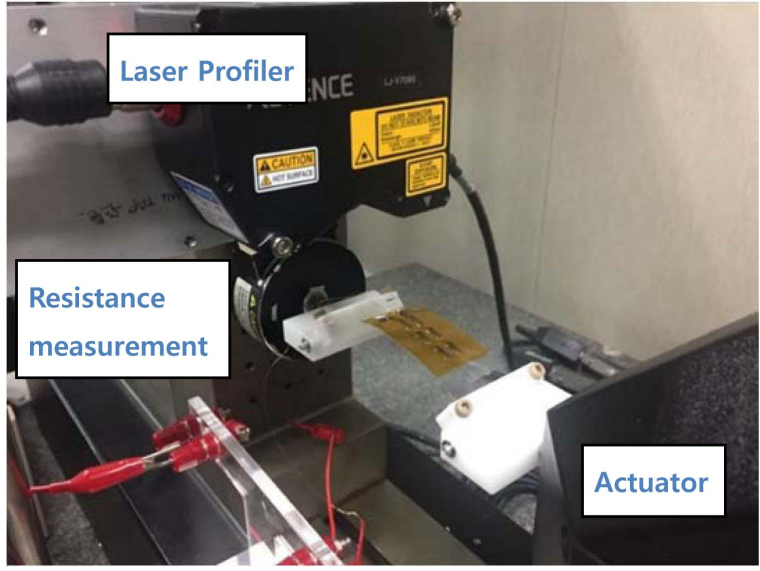

Fig. 5. Repeated bending test equipment of flexible thermoelectric device.

ble thermoelectric device and the detector measures the laser reflected off the curvature of the device; the resistance was measured using the sourcemeter. Resistance variation according to the cycles carried out at $0.5 \mathrm{~Hz}$ in the bending radius range of $30 \mathrm{~mm} \sim 100 \mathrm{~mm}$ was measured to assess the reliability of the fabricated flexible thermoelectric device.

\section{Results and Discussion}

\subsection{Thermoelectric Material Properties}

Figure 6 shows the SEM analysis results for the $\mathrm{Sb}_{2} \mathrm{Te}_{3}$ and $\mathrm{Bi}_{2} \mathrm{Te}_{3}$ specimens according to the load. As can be observed in Figs. 6(a) and (c), when a load of $22.2 \mathrm{kN}$ was applied to the specimens, the particle size of $\mathrm{Bi}_{2} \mathrm{Te}_{3}$ was smaller and more uniform than that of $\mathrm{Sb}_{2} \mathrm{Te}_{3}$, resulting in
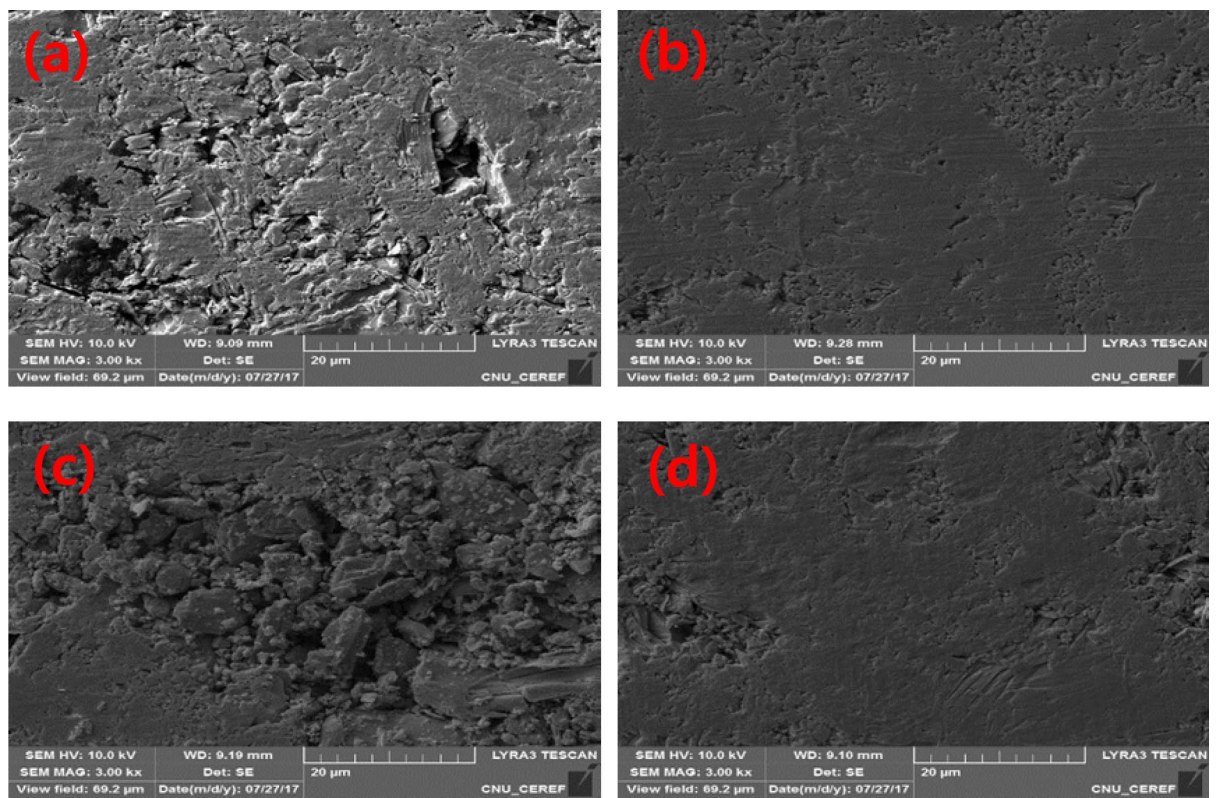

Fig. 6. $\mathrm{SEM}$ images of the $\mathrm{Sb}_{2} \mathrm{Te}_{3}$ specimen pressed with (a) $34.37 \mathrm{KN}$ and (b) $33.3 \mathrm{KN}$ and $\mathrm{Bi}_{2} \mathrm{Te}_{3}$ specimen pressed with (c) $34.37 \mathrm{KN}$ and (d) $33.3 \mathrm{KN}$. 
Table 1. Thermoelectric Properties of $\mathrm{Sb}_{2} \mathrm{Te}_{3}$ and $\mathrm{Bi}_{2} \mathrm{Te}_{3}$ with Load

\begin{tabular}{cccccccc}
\hline No. & Material & $\begin{array}{c}\text { Load } \\
(\mathrm{KN})\end{array}$ & $\begin{array}{c}\text { Thickness } \\
(\mu \mathrm{m})\end{array}$ & $\begin{array}{c}\text { Mobility } \\
\left(\mathrm{cm}^{2} / \mathrm{Vs}\right)\end{array}$ & $\begin{array}{c}\text { Seebeck } \\
(\mu \mathrm{V} / \mathrm{K})\end{array}$ & $\begin{array}{c}\text { Resistivity } \\
(\mu \Omega \cdot \mathrm{m})\end{array}$ & $\begin{array}{c}\text { Power factor } \\
\left(\mathrm{mW} / \mathrm{mK}^{2}\right)\end{array}$ \\
\hline $\mathrm{ST} 1$ & $\mathrm{Sb}_{2} \mathrm{Te}_{3}$ & 22.2 & 850 & 35.6 & 180 & 35.6 & 0.91 \\
$\mathrm{ST} 2$ & $\mathrm{Bi}_{2} \mathrm{Te}_{3}$ & 33.3 & 840 & 123 & 188 & 23.0 & 1.53 \\
$\mathrm{BT} 1$ & $\mathrm{Sb}_{2} \mathrm{Te}_{3}$ & 22.2 & 850 & 44.3 & -241 & 33.7 & 1.72 \\
$\mathrm{BT} 2$ & $\mathrm{Bi}_{2} \mathrm{Te}_{3}$ & 33.3 & 840 & 88 & -223 & 23.4 & 2.13 \\
\hline
\end{tabular}

smaller voids. As can be observed in Figs. 6(b) and (d), when the load was increased to $33.3 \mathrm{kN}$, both $\mathrm{Sb}_{2} \mathrm{Te}_{3}$ and $\mathrm{Bi}_{2} \mathrm{Te}_{3}$ showed decreased voids and increased density, such that the two specimens had similar densities.

Table 1 shows the thermoelectric properties of $\mathrm{Sb}_{2} \mathrm{Te}_{3}$ and $\mathrm{Bi}_{2} \mathrm{Te}_{3}$ according to the load. The Seebeck coefficients for the $\mathrm{Sb}_{2} \mathrm{Te}_{3}$ specimens were $-188 \mu \mathrm{V} / \mathrm{K}$ for the $22.2 \mathrm{kN}$ load specimen (ST1) and $-180 \mu \mathrm{V} / \mathrm{K}$ for the $33.3 \mathrm{kN}$ load specimen (ST2). On the other hand, the Seebeck coefficients for the $\mathrm{Bi}_{2} \mathrm{Te}_{3}$ specimens were $-241 \mu \mathrm{V} / \mathrm{K}$ for the $22.2 \mathrm{kN}$ load specimen (BT1) and $-223 \mu \mathrm{V} / \mathrm{K}$ for the $33.3 \mathrm{kN}$ load specimen (BT2).

Although there are slight differences in the Seebeck coefficients, the coefficients for both the $\mathrm{Sb}_{2} \mathrm{Te}_{3}$ and $\mathrm{Bi}_{2} \mathrm{Te}_{3}$ specimens did not change significantly. The electrical resistivity values were $35.6 \mu \Omega \cdot \mathrm{m}$ and $23 \mu \Omega \cdot \mathrm{m}$ for ST1 and ST2, respectively. When the load was increased 1.5 times, the resistivity decreased by approximately $35 \%$. On the other hand, the electrical resistivity values for BT1 and BT2 were $35.6 \mu \Omega \cdot \mathrm{m}$ and $23 \mu \Omega \cdot \mathrm{m}$, respectively. When the load was increased 1.5 times, the resistivity decreased by roughly $30 \%$.

The mobility of $\mathrm{Sb}_{2} \mathrm{Te}_{3}$ increased roughly 3 times from $35.6 \mathrm{~cm}^{2} / \mathrm{Vs}$ to $123 \mathrm{~cm}^{2} / \mathrm{Vs}$ when the load was increased, while the mobility of $\mathrm{Bi}_{2} \mathrm{Te}_{3}$ increased roughly 2 times from $44.3 \mathrm{~cm}^{2} / \mathrm{Vs}$ to $88.4 \mathrm{~cm}^{2} / \mathrm{Vs}$. The electrical resistivity showed a reciprocal relationship with the electrical conductivity; this relationship can be expressed using the following equation. $^{13)}$

$$
\sigma=\text { ne } \mu
$$

Here, $\sigma$ refers to the electrical conductivity, $e$ refers to the electronic charge, and $\mu$ refers to the mobility. As is evident in Eq. (1), when the mobility increases, the electrical conductivity increases, while the electrical resistivity decreases.

The power factor represents the thermoelectric property and can be expressed as Eq. (2). ${ }^{14)}$

$$
\mathrm{PF}=\sigma S^{2}
$$

Here, $\sigma$ refers to the electrical conductivity and $S$ refers to the Seebeck coefficient.

The power factors of ST1 and ST2 were $0.91 \mathrm{~mW} / \mathrm{m} \cdot \mathrm{K}^{2}$ and $1.53 \mathrm{~mW} / \mathrm{m} \cdot \mathrm{K}^{2}$, revealing that the power factor increased by approximately $70 \%$ according to the load. The power factors of BT1 and BT2 were $1.47 \mathrm{~mW} / \mathrm{m} \cdot \mathrm{K}^{2}$ and $2.13 \mathrm{~mW} / \mathrm{m} \cdot \mathrm{K}^{2}$. The power factors increased by roughly $45 \%$. When the load was $33.3 \mathrm{kN}, \mathrm{Sb}_{2} \mathrm{Te}_{3}$ and $\mathrm{Bi}_{2} \mathrm{Te}_{3}$ showed almost no difference in electrical resistivity, while the power factor of $\mathrm{Bi}_{2} \mathrm{Te}_{3}$ was approximately 1.4 times larger because the Seebeck coefficient of $\mathrm{Bi}_{2} \mathrm{Te}_{3}$ was larger.

\subsection{Flexible Thermoelectric Device Performance Evaluation}

The performance assessment equipment shown in Fig. 4 was used to evaluate the power generation performance of the fabricated flexible thermoelectric devices according to the temperature difference. Fig. 7 shows the voltage-current and power output-current curves of the flexible thermoelectric device when the temperature differences were $10^{\circ} \mathrm{C}$, $30^{\circ} \mathrm{C}$, and $50^{\circ} \mathrm{C}$. The voltage-current curve shows inversely proportional lines with the same slope for the three different temperatures.

The voltage and current of the closed circuit thermoelectric device can be expressed using Eq. (3). ${ }^{15}$

$$
\mathrm{V}=S \Delta \mathrm{T}-\mathrm{rI}
$$

Here, I refers to the current, $r$ refers to the internal resistance, $\mathrm{V}$ refers to the voltage, and $\Delta \mathrm{T}$ refers to the temperature difference.

According to Eq. (3), the current and voltage have an inversely proportional relationship, which is in agreement with the results shown in Fig. 7.

When the current becomes 0 in Eq. (3), the open circuit voltage can be obtained. In Fig. 7, when the temperature difference was $50^{\circ} \mathrm{C}$, the open circuit voltage was $43.5 \mathrm{mV}$.

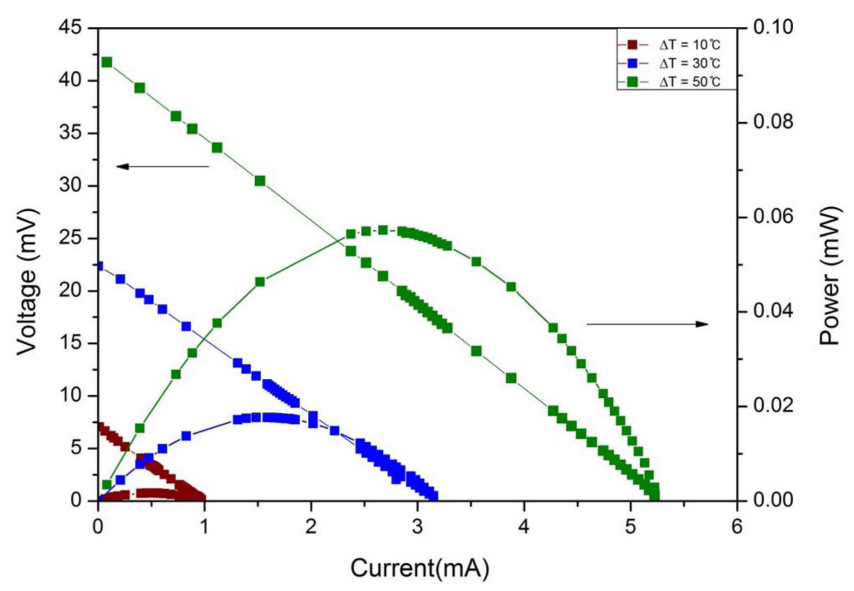

Fig. 7. Voltage - current and power output - current relationships. 


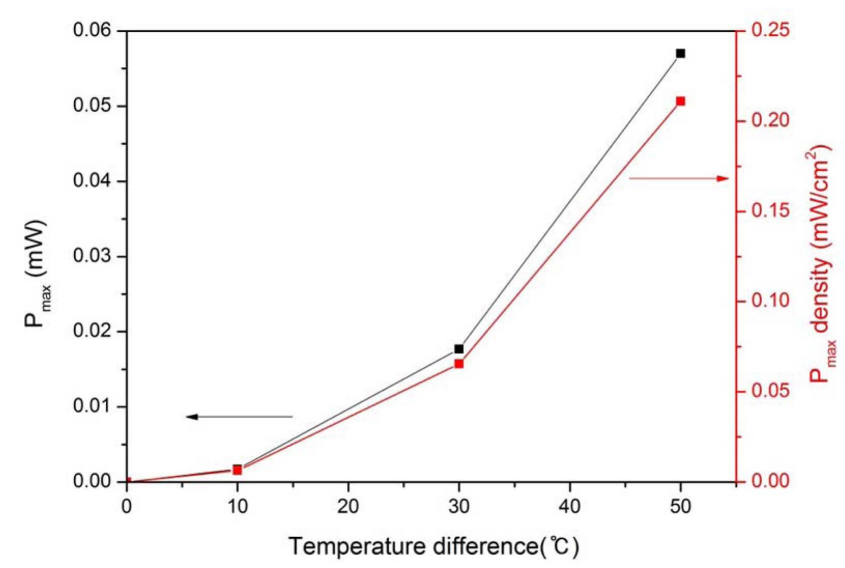

Fig. 8. Power output and power density with temperature difference.

When the voltage is 0 , the maximum current can be obtained. When the temperature difference was $50^{\circ} \mathrm{C}$, the maximum current was $5.2 \mathrm{~mA}$.

The relationship between the power output and the current for the closed circuit thermoelectric device can be expressed as Eq. (4). ${ }^{16)}$

$$
\mathrm{P}=S \Delta \mathrm{T} \cdot \mathrm{I}-\mathrm{r} I^{2}
$$

Here, $\mathrm{P}$ refers to the power output. According to Eq. (4), the power output-current curve is a parabolic curve flipped upside down, which is in agreement with the results shown in Fig. 7. The maximum power output of the thermoelectric device was obtained when the maximum current was $1 / 2$; the maximum power output was determined to be $0.057 \mathrm{~mW}$ when the temperature difference was $50^{\circ} \mathrm{C}$. Fig. 8 shows the power output-temperature difference and the power density-temperature difference relationship curves. Here, the power density is the power output divided by the total cross section area of the leg. As the temperature difference increased, the power output and power density increased parabolically and the power density was $0.2 \mathrm{~mW} / \mathrm{cm}^{2}$ for the temperature difference of $50^{\circ} \mathrm{C}$.

\subsection{Reliability Evaluation According to Bending Radius of Flexible Thermoelectric Device}

Figure 9 shows the flexible thermoelectric device under bending load. When the resistance of the flexible thermoelectric device increases, the power output decreases, resulting in performance degradation. So, measuring the resistance variation according to the bending is important. In order to assess the flexibility of the flexible thermoelectric device, the resistance change was measured as the bending radius was varied from $94.77 \mathrm{~mm} \sim 7.46 \mathrm{~mm}$. Fig. 10 shows the rate of change of the resistance according to the bending radius. The rate of change of resistance for the flexible thermoelectric device with initial internal resistance of approximately $0.36 \Omega$ was $2.8 \%$ when the bending radius was 94.77 $\mathrm{mm} \sim 9.86 \mathrm{~mm}$; the rate of change of the resistance was $6.9 \%$ when the bending radius was $8.06 \mathrm{~mm}$. When the

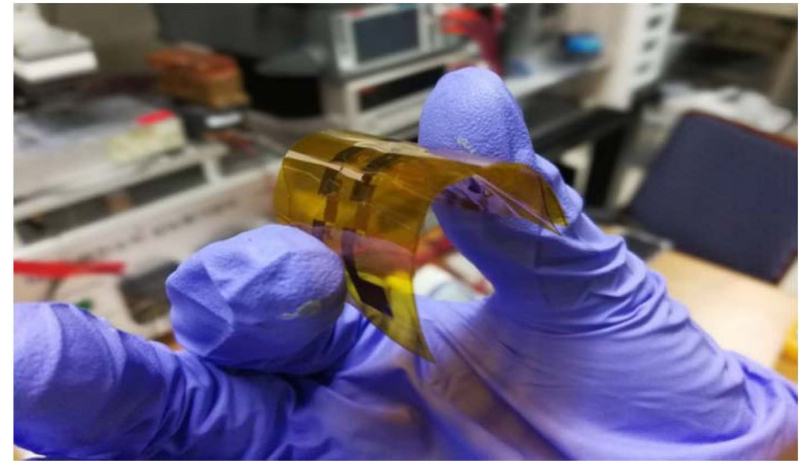

Fig. 9. Demonstration of bending of flexible thermoelectric device.

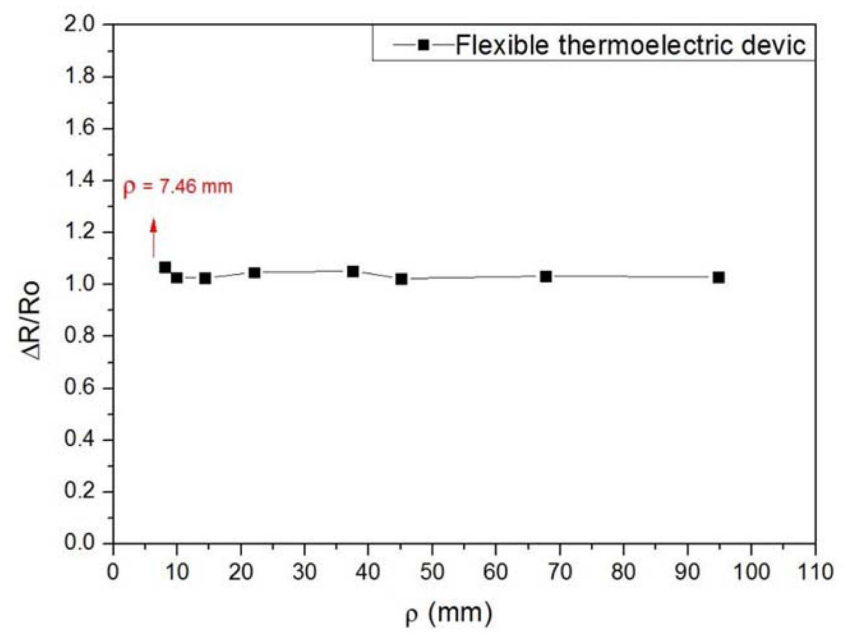

Fig. 10. Rate of change of resistance according to bending radius.

bending radius was $7.46 \%$, the rate of change of the resistance increased rapidly and resulted in failure of the device. Even when the bending radius of the flexible thermoelectric device was reduced to $8.06 \mathrm{~mm}$, the resistance change was not large, leading to the conclusion that there will be no power generation performance degradation.

Figure 11 shows the rate of change of the resistance according to the number of bending cycles for the flexible thermoelectric device. Through this, the lifespan of the fabricated flexible thermoelectric device can be predicted. The initial resistance of the flexible thermoelectric device when installed in the fatigue testing machine was approximately $0.83 \Omega$. Initially, a stabilization interval was observed up to the first 100 cycles, during which the resistance decreased to approximately $0.75 \Omega$. There was almost no change in the internal resistance up to around 3100 cycles. At 3142 cycles, failure of the device occurred and the resistance was on the order of $M \Omega$. Thus, for a heat source with a bending radius between $30 \mathrm{~mm} \sim 100 \mathrm{~mm}$, it was determined that the fabricated flexible thermoelectric device did not show resistance change even after repeated attachment and detachment up to around 3100 cycles. Therefore, the power generation per- 


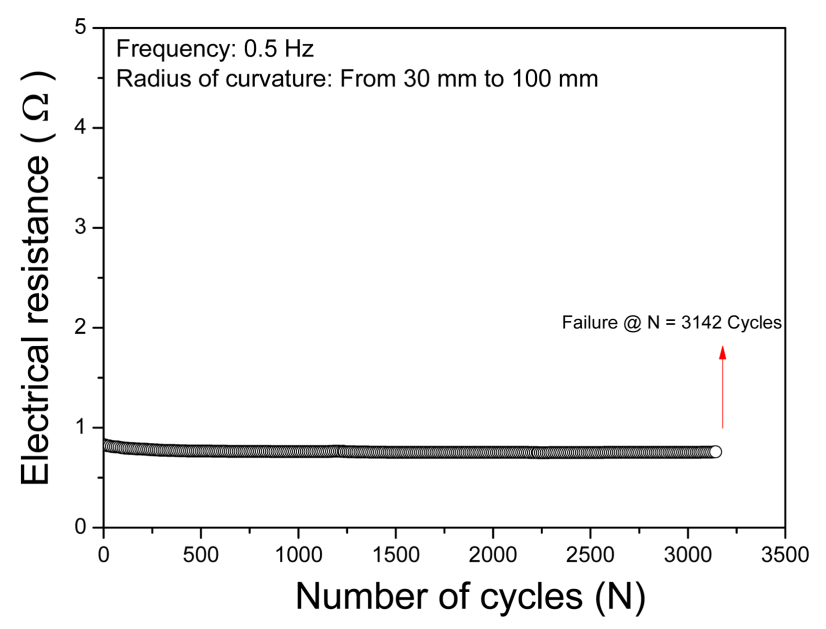

Fig. 11. Rate of change of resistance according to number of cycles.

formance of the flexible thermoelectric device was maintained.

\section{Conclusions}

In this study, using the cold press method, $\mathrm{Sb}_{2} \mathrm{Te}_{3}$ and $\mathrm{Bi}_{2} \mathrm{Te}_{3}$ powders were used as base material to fabricate thick film thermoelectric material. Next, a manufactured thermoelectric leg on a PI substrate was used to fabricate flexible thermoelectric devices.

The cold press method is low cost in terms of fabrication of thermoelectric thick film; the process is very simple, with no post processing steps, while allowing for mass production. It was observed that thermoelectric thick films under load experienced increased mobility and decreased resistance of the thermoelectric thick films. The decrease in the electrical resistivity of the thermoelectric thick films led to power factor enhancement.

The flexible thermoelectric device process developed in this study used a bonding process through solder paste and the screen printing method. The process is simple, the fabrication is convenient, and the resulting devices show excellent flexibility.

Application of the developed flexible thermoelectric device to power generation using human body heat is expected to yield a temperature difference of around $10^{\circ} \mathrm{C}$ between the body heat and the ambient temperature. According to the results of this study, when the temperature difference was $10^{\circ} \mathrm{C}$, the maximum power output was $1.7 \mu \mathrm{W}$ and the power density was $6.4 \mu \mathrm{W} / \mathrm{cm}^{2}$. When the total leg area of the flexible thermoelectric device is manufactured to 9.4 $\mathrm{cm}^{2}$, a power output of approximately $60 \mu \mathrm{W}$ can be produced and can be utilized as a power source for a wearable oximeter with a power consumption of $60 \mu \mathrm{W}$. $^{8)}$

The human body has curved surfaces, so flexibility is important for the application of flexible thermoelectric devices to wearable devices. The fabricated flexible thermo- electric devices showed virtually no change in internal resistance when bending radii of $94.77 \mathrm{~mm} \sim 8.06 \mathrm{~mm}$ were applied. The flexible thermoelectric devices underwent failure at around 3100 cycles when repeated bending at the bending radius of $30 \mathrm{~mm} \sim 100 \mathrm{~mm}$ was applied. Thus, the durability of the flexible thermoelectric device against attachment and detachment to a heat source was determined to be approximately 3100 cycles. Therefore, since the human wrist generally has a bending radius of $30 \mathrm{~mm},{ }^{17}$ ) the fabricated flexible thermoelectric device is expected to be applicable to wearable devices because the fabricated device showed no power output degradation.

The developed flexible thermoelectric devices are also expected to be used in various fields because they can be applied to heat sources having curvature on the surfaces.

\section{REFERENCES}

1. Z.-G. Chen, G. Han, L. Yang, L. Cheng, and J. Zou, "Nanostructured Thermoelectric Materials: Current Research and Future Challenge," Prog. Nat. Sci.: Mater. Int., 22 [6] 535-49 (2012).

2. X. Yan, S. Populoh, A. Weidenkaff, P. Rogl, and S. Paschen, "Chemical and Thermoelectric Properties of Hot Pressed and Spark Plasma Sintered Type -1 Clathrate $\mathrm{Ba}_{8} \mathrm{Cu}_{4.8} \mathrm{Si}_{41.2}$," J. Electron. Mater., 45 [3] 1800-44 (2016).

3. M. Christensen and A. B. Abrahamsen, N. B. Christensen, F. Juranyi, N. H. Andersen, K. Lefmanin, J. Andreasson, C. R. H. Bahl, and B. B. Iversen, "Avoided Crossing of Rattler Modes in Thermoelectric Materials," Nat. Mater., 7 811-15 (2008).

4. J. P. Heremans, V. Jovovic, E. S. Toberer, A. Saramat, K. Kurosaki, A. Charoenphakdee, S. Yamanaka, and G. J. Snyder, "Enhancement of Thermoelectric Efficiency in PbTe by Distortion of the Electronic Density of States," Science, 321 [5888] 554-57 (2008).

5. K. T. Kim, H. Y. Koo, and G. H. Ha, "Influence of MetalCoating Layer on an Electrical Resistivity of Thick-FilmType Thermoelectric Modules Fabricated by a Screen Printing Process (in Korean)," J. Korea Powder Metall. Inst., 18 [5] 423-29 (2011).

6. Y. S. Song, I. J. Yoo, N. R. Heo, D. C. Lim, D. Y. Lee, J. Y. Lee, K. H. Lee, K. H. Kim, and J. H. Lim, "Electrodeposition of Thermoelectric $\mathrm{Bi}_{2} \mathrm{Te}_{3}$ Thin films with Added Surfactant," Curr. Appl. Phys., 15 [3] 261-64 (2015).

7. C. Navone, M. Soulier, M. Plissonnier, and A. L. Seiler, "Development of $(\mathrm{Bi}, \mathrm{Sb})_{2}(\mathrm{Te}, \mathrm{Se})_{3}$-Based Thermoelectric Modules by a Screen-Printing Process," J. Electron. Mater., 39 [9] 1755-59 (2010).

8. J. H. Bahk, H. Fang, K. Yazawa, and A. Shakouri, "Flexible Thermoelectric Materials and Device Optimization for Wearable Energy Harvesting," J. Mater. Chem. C, 3 [40] 10362-74 (2015).

9. K. Suemori, S. Hoshino, and T. Kamata, "Flexible and Lightweight Thermoelectric Generators Composed of Carbon Nanotube-Polystyrene Composites Printed on Film Substrate," Appl. Phys. Lett., 103 [15] 153902 (2013).

10. Z. Lu, M. Layanil, X. Zhao, L. P. Tan, T. Sun, S. Fan, Q. 
Yan, S. Magdassi, and H. H. Hng, "Fabrication of Flexible Thermoelectric Thin Film Devices by Inkjet Printing," Small, 10 [17] 3551-54 (2014).

11. M. Usma, I. H. Kim, and H. J. Jung, "Improving Thermoelectric Energy Harvesting Efficiency by Using Graphene," AIP Adv., 6 [5] 055027 (2016).

12. M. L. Lwin, S. M. Yoon, B. Madavali, C. H. Lee, and S. J. Hong, "Investigation of Ball Size Effect on Microstructure and Thermoelectric Properties of p-type BiSbTe by Mechanical Alloying,"J. Korean Powder Metall. Inst., 23 [2] 120-25 (2016).

13. X. Zaang and L. D. Zhoa, "Thermoelectric Materials: Energy Conversion between Heat and Electricity," J. Materiomics., 1 [2] 92-105 (2015).

14. A. M. Dehkordi, M. Zebarjadi, J. He, and T. M. Tritt,
"Thermoelectric Power Factor: Enhancement Mechanisms and Strategies for Higher Performance Thermoelectric Materials," Mater. Sci. Eng., 97 1-22 (2015).

15. A. Montecucco, J. Siviter, and A. R. Knox "The Effect of Temperature Mismatch on Thermoelectric Generators electrically Connected in Series and Parallel," Appl. Energy, 123 [15] 47-54 (2014).

16. W. H. Chen, S. R. Huang, and Y. L. Lin, "Performance Analysis and Optimum Operation of a Thermoelectric Generator by Taguchi Method," Appl. Energy, 158 44-54 (2015).

17. Human Wrist, http://www.lgchem.com/kr/lg-chem-company/ information-center/press-release/news-detail-2174. Accessed on $05 / 10 / 2017$. 